This item is the archived peer-reviewed author-version of:

\title{
Luminescent quantum dots by partial cation exchange in nanocrystals
}

\section{Reference:}

van der Stam Ward, Berends Anne C., Rabouw Freddy T., Willhammar Tom, Ke Xiaoxing, Meeldijk Johannes D., Bals Sara, de Donega Celso Mello.- Luminescent quantum dots by partial cation exchange in nanocrystals

Chemistry of materials - ISSN 0897-4756 - 27:2(2015), p. 621-628

Full text (Publishers DOI): http://dx.doi.org/doi:10.1021/CM504340H

To cite this reference: http://hdl.handle.net/10067/1252910151162165141 


\title{
Luminescent CulnS $_{2}$ quantum dots by partial cation exchange in $\mathrm{Cu}_{2-\mathrm{x}} \mathrm{S}$ nanocrystals
}

\author{
Ward van der Stam¹, Anne C. Berends ${ }^{1}$, Freddy T. Rabouw ${ }^{1}$, Tom Willhammar ${ }^{2}$, Xiaoxing $\mathrm{Ke}^{2}$, \\ Johannes D. Meeldijk³, Sara Bals ${ }^{2}$, and Celso de Mello Donega*
}

1 Condensed Matter and Interfaces, Debye Institute for Nanomaterials Science, Utrecht University, Princetonplein 5, 3584 CC Utrecht, The Netherlands

2 Electron Microscopy for Materials Science (EMAT), University of Antwerp, Groenenborgerlaan 171, B-2020 Antwerp, Belgium

3 Electron Microscopy Utrecht, Debye Institute for Nanomaterials Science, Utrecht University, $3584 \mathrm{CH}$ Utrecht, The Netherlands

KEYWORDS copper chalcogenides, partial cation exchange, ternary nanocrystals, NIR Photoluminescence, CuInS ${ }_{2}$

\begin{abstract}
Here, we show successful partial cation exchange reactions in $\mathrm{Cu}_{2-\mathrm{x}} \mathrm{S}$ nanocrystals ( $\mathrm{NCs}$ ) yielding luminescent $\mathrm{CuInS}_{2}$ (CIS) NCs. Our approach of mild reaction conditions ensures slow $\mathrm{Cu}$-extraction rates which results in a balance with the slow In-incorporation rate. With this method, we obtain CIS NCs with photoluminescence (PL) far in the near-infrared (NIR), which cannot be directly synthesized by currently available synthesis protocols. We discuss the factors that favor partial, selflimited cation exchange from $\mathrm{Cu}_{2-\mathrm{x}} \mathrm{S}$ to CIS NCs, rather than

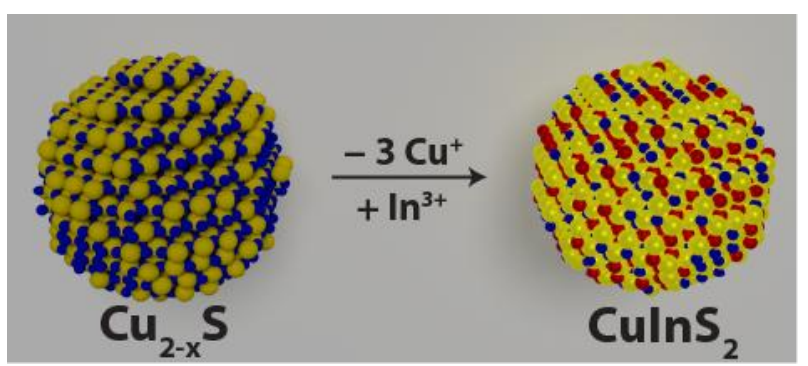
complete cation exchange to $\operatorname{In}_{2} \mathrm{~S}_{3}$. The product CIS NCs have the wurtzite crystal structure, which is understood in terms of conservation of the hexagonal close packing of the anionic sublattice of the parent NCs into the product NCs. These results are an important step toward the design of CIS NCs with sizes and shapes that are not attainable by direct synthesis protocols and may thus impact on a number of potential applications.
\end{abstract}

\section{Introduction}

Colloidal semiconductor nanocrystals (NCs) have attracted increasing attention due to their exciting and tunable optical properties, which render them promising materials for several applications. ${ }^{1-4}$ For example, NCs can be used as luminescent probes for in vivo bio-imaging, ${ }^{5,6}$ as well as light converters in displays and LEDs. ${ }^{7,8}$ However, the presence of heavy metals such as cadmium and lead is an increasing concern, which limits the applicability of colloidal NCs. ${ }^{8,9}$

Copper indium dichalcogenide $\left(\mathrm{CuInE}_{2}\right.$, with $\mathrm{E}=\mathrm{S}$ and/or Se) NCs have optical properties that can be tuned in the visible to the near-infrared (potentially up to $855 \mathrm{~nm}$ for $\mathrm{CuInS}_{2}$, CIS, and up to $1215 \mathrm{~nm}$ for CuInSe 2 , CISe) spectral range, which makes them promising alternatives for the well-known heavy metal based $\mathrm{NCs}(\mathrm{CdE}$ and $\mathrm{PbE}$, with $\mathrm{E}$ $=\mathrm{S}, \mathrm{Se}, \mathrm{Te}) \cdot{ }^{10-14}$ For example, the direct bandgap of $1.45 \mathrm{eV}$ and large absorption coefficients make CIS a suitable alternative absorber material for quantum dot and thin film photovoltaics (PV). ${ }^{15^{-17}}$ Additionally, the small self- absorption cross-section ${ }^{10}$ makes CIS NCs very interesting materials as luminophores in luminescent solar concentrators. ${ }^{18,19}$

However, the currently available protocols for the direct colloidal synthesis of luminescent ternary NCs such as CIS and CISe produce only small quasi-spherical $\mathrm{NCs}^{10-12}$ Larger and anisotropic NCs with a homogeneous composition are difficult to obtain because multiple precursor reactivities need to be balanced for simultaneous thermolysis of the cationic precursors. ${ }^{20}$ Otherwise, it is favorable for the reaction system to form instead binary NCs, such as $\mathrm{Cu}_{2-\mathrm{x}} \mathrm{S}^{21}$ Pure phase luminescent quasi-spherical CIS NCs have only been obtained with photoluminescence (PL) peak between 550 and $750 \mathrm{~nm},{ }^{22,23}$ whereas large non-luminescent CIS nanorods are obtained when $\mathrm{Cu}_{2-\mathrm{x}} \mathrm{S}$ NCs are used in situ as nucleation seeds. ${ }^{24}$ Hence, there is a wide range of sizes and shapes that have not yet been explored for CIS NCs.

Here, we present a synthetic pathway towards ternary $\mathrm{CuInS}_{2} \mathrm{NCs}$ from binary $\mathrm{Cu}_{2-\mathrm{S}} \mathrm{S}$ parent $\mathrm{NCs}$ by exploiting 
cation exchange (CE) reactions. ${ }^{25-28}$ Non-luminescent $\mathrm{Cu}_{2-}$ ${ }_{\mathrm{x}} \mathrm{S}$ NCs are converted into luminescent CIS NCs, where the PL peak position of the product CIS NCs is determined by the size of the parent $\mathrm{Cu}_{2-\mathrm{X}} \mathrm{S}$ NCs. This method allows us to synthesize CIS NCs with PL in the nearinfrared (NIR) centred at $870 \mathrm{~nm}$, which are not attainable in a direct fashion. Since $\mathrm{Cu}_{2-\mathrm{x}} \mathrm{S}$ NCs can be synthesized with large control over size and shape, ${ }^{29-31}$ the method described in this work may provide a pathway to prepare colloidal CIS NCs of as yet unexplored morphologies and functionalities.

\section{Experimental section \\ Materials}

Copper(I) acetate (CuOAc, 97\%), Copper sulfate pentahydrate $\left(\mathrm{CuSO}_{4} .5 \mathrm{H}_{2} \mathrm{O}, \geq 98 \%\right)$ indium nitrate hydrate $\left(\mathrm{In}\left(\mathrm{NO}_{3}\right)_{3} \cdot \mathrm{H}_{2} \mathrm{O}, 99 \cdot 99 \%\right)$, 1-dodecanethiol (DDT, $\left.\geq 98 \%\right)$, 1octadecene (ODE, 90\%), tri-octyl phosphine oxide (TOPO, 99\%), tri-octyl phosphine (TOP, 90\%), oleic acid (OA, 90\%), anhydrous toluene, methanol and butanol were purchased from Sigma Aldrich. ODE and TOPO were degassed prior to synthesis, all other materials were used as received.

\section{Synthesis of $2.5 \mathrm{~nm} \mathrm{Cu_{2-x }} \mathrm{S}$ NCs}

The $\mathrm{Cu}_{2-\mathrm{x}} \mathrm{S}$ NCs (size: $2.5 \mathrm{~nm}$ ) were synthesized according to the method described by Wang et $a .^{32}$ In a roundbottom flask, $0.3 \mathrm{mmol} \mathrm{CuOAc}$ and $1.1 \mathrm{~g}$ TOPO were dissolved in $25 \mathrm{~mL}$ previously degassed ODE. After additional degassing for one hour at $100{ }^{\circ} \mathrm{C}$ the reaction mixture was further heated to $160{ }^{\circ} \mathrm{C}$ and $1 \mathrm{~mL}$ DDT was swiftly injected into the dark green solution under $\mathrm{N}_{2}$ atmosphere. The NCs were allowed to grow for 90 minutes. Subsequently, the NCs were cooled to room temperature. They were washed by adding methanol and butanol (1:1 ratio) , centrifugation at $3000 \mathrm{rpm}$ for several minutes., and redispersion in $2 \mathrm{~mL}$ toluene. This cycle was repeated 3 times.

\section{Synthesis of $4 \mathrm{~nm} \mathrm{Cu}_{2-\mathrm{x}} \mathrm{S}$ NCs}

For the synthesis of $4 \mathrm{~nm}$ sized $\mathrm{Cu}_{2-\mathrm{x}} \mathrm{S}$ nanocrystals the same procedure as described above was followed, only the NCs were allowed to grow for an additional 2 hours (overall growth time; 3.5 hours). The same washing steps were performed.

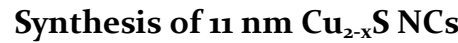

The $11 \mathrm{~nm}$ sized $\mathrm{Cu}_{2-\mathrm{x}} \mathrm{S}$ nanocrystals were synthesized according to an adaptation of the method described by $\mathrm{Lu}$ et al. $^{24}$ In a round-bottom flask, $0.8 \mathrm{mmol} \mathrm{CuSO}_{4} .5 \mathrm{H}_{2} \mathrm{O}$ (203 mg), 7.5 mL DDT and $6 \mathrm{~mL} \mathrm{OA}$ were mixed and gradually heated to $200{ }^{\circ} \mathrm{C}$. Total heating time was 15 minutes, after which the solution was maintained at 200 ${ }^{\circ} \mathrm{C}$ for 2 hours. The crude reaction mixture was purified in the same way as described above and redispersed in $\sim 5$ mL toluene.

\section{Cation exchange (CE) reactions of $\mathrm{Cu}^{+}$for $\mathrm{In}^{3+}$}

The cation exchange reactions were performed according to an adaptation of the method described by Son et al. for $\mathrm{Cd}^{2+}$ for $\mathrm{Ag}^{+}$exchange reactions. ${ }^{26} 1 \mathrm{~mL} \mathrm{Cu}_{2-\mathrm{x}} \mathrm{S} \mathrm{NCs}\left(\sim 10^{-8}\right.$ $\mathrm{M})$ in toluene was diluted three times and $0.14 \mathrm{mmol}$ $\mathrm{In}\left(\mathrm{NO}_{3}\right)_{3} \cdot \mathrm{H}_{2} \mathrm{O}$ dissolved in $1 \mathrm{~mL}$ methanol was added. The
In:Cu molar ratio was $\sim 1$ for all NC sizes. This ratio was estimated by assuming quantitative reaction and no purification losses. Finally, 10o $\mu \mathrm{L}$ TOP was added as $\mathrm{Cu}-$ extracting ligand and the solution was stirred for several days. The NCs were thoroughly washed to remove excess precursor and ligands by adding methanol and butanol (1:1 ratio) and centrifugation at $3000 \mathrm{rpm}$ for several minutes. Subsequently, the NCs were dispersed in $2 \mathrm{~mL}$ toluene.

\section{Optical spectroscopy}

Samples for optical measurements were prepared by diluting the washed NCs with anhydrous toluene under nitrogen and stored in sealed cuvettes. Absorption spectra were measured on a double beam Perkin-Elmer Lambda $16 \mathrm{UV} / \mathrm{Vis}$ spectrometer. PL and PL excitation spectra were recorded by an Edinburgh Instruments FLS920 Spectrofluorimeter equipped with a $45^{\circ} \mathrm{W}$ Xenon lamp as excitation source and double grating monochromators. PL decay curves were obtained by time-correlated singlephoton counting via time-to-amplitude conversion. A pulsed diode laser (EPL-445 Edinburgh Instruments, 441 $\mathrm{nm}, 55 \mathrm{ps}$ pulse width, $0.2-0.5 \mathrm{MHz}$ repetition rate) was used as the excitation source.

\section{Transmission Electron Microscopy}

Transmission Electron Microscopy (TEM) and Energy Dispersive X-Ray Spectroscopy (EDS) were performed using a FEI Tecnai-12 microscope operating at $120 \mathrm{kV}$ and a FEI Tecnai-2oF microscope operating at $200 \mathrm{kV}$. Samples for TEM imaging were prepared by drop-casting a toluene solution of NCs onto a carbon-coated copper (400-mesh) TEM grid. The excess liquid was removed by blotting using filter paper.

\section{Energy Dispersive X-ray Spectroscopy mapping}

Scanning TEM EDS measurements were performed on a FEI Tecnai-2oF microscope operating at $200 \mathrm{kV}$. EDS measurements were performed using a dedicated low background holder and $\mathrm{Cu}$-free $\mathrm{Ni}$ TEM grids. Acquisition time for EDS measurements was $\sim 30 \mathrm{~s}-\sim 1 \mathrm{~min}$. To ensure that the elemental concentrations were statistically valid and representative of the whole NC ensemble, EDS analyses were performed on wide areas $\left(10^{4}-10^{5} \mathrm{~nm}^{2}\right)$, encompassing several thousands of NCs. We note here that even when taking the usual precautions (dedicated low background holder and $\mathrm{Cu}$-free $\mathrm{Ni}$ TEM grids), there is always a background $\mathrm{Cu}$ signal contributing to the EDS spectrum. We estimated the uncertainty in the composition of the NCs by averaging values obtained for different samples. Since the elemental ratios are defined with respect to $S$, standard deviation values are not provided for the $S$ ratios.

The EDS-signal is acquired with an EDAX $\mathrm{Si}(\mathrm{Li})$ detector and processed in Tecnai Imaging and Analysis software (TIA), using the following lines: S-K at $2.3 \mathrm{keV}$, In-L at 3.3 $\mathrm{keV}$ and $\mathrm{Cu}-\mathrm{K}$ at $8.0 \mathrm{keV}$. The $\mathrm{S}-\mathrm{K}$ and $\mathrm{In}-\mathrm{L}$ are well resolved but $\mathrm{Cu}-\mathrm{K}$ is partially overlapping with the $\mathrm{Ni}-\mathrm{K} \beta$ peak at $8.26 \mathrm{keV}$ (originating from the nickel grid). The software deconvoluted these two peaks. The automatically acquired background subtraction was adjusted manually where necessary in order to quantitatively deconvolute 
the peaks and no thickness or ZAF corrections were applied.

High-Resolution Scanning Transmission Electron Microscopy (HRSTEM)

High-Resolution Scanning Transmission Electron Microscopy (HRSTEM) images of the CIS NCs were acquired using an FEI Titan ${ }^{3}$ operated at an accelerating voltage of $120 \mathrm{kV}$. The images were collected using a high angle annular dark field (HAADF) detector. The samples were prepared by adding a droplet of the toluene dispersion to a carbon coated copper grid. The lattice averaging were performed by calculating a Fast Fourier transform (FFT) from the area of interest, extracting one Fourier component from each of the lattice points of the FFT and perform an inverse Fourier transform to create the final map. The image processing was performed using the software CRISP. ${ }^{33}$

\section{$\mathrm{X}$-ray Diffractometry}

X-ray Diffraction (XRD) measurements were performed with a Bruker D2 Phaser, equipped with a Co K $\alpha$ X-ray source with X-ray wavelength of $1.79026 \AA$. Thin solid film NC samples for XRD were prepared by drop-casting a concentrated NC solution in chloroform on a Si wafer and evaporating the solvent.

\section{Results \& Discussion}

$2.5 \mathrm{~nm}$ CIS NCs by partial cation exchange in $\mathrm{Cu}_{2-\mathrm{x}} \mathrm{S}$ NCs. Non-luminescent $2.5 \mathrm{~nm} \mathrm{Cu}_{2-\mathrm{x}} \mathrm{S}$ nanocrystals (NCs), with a first absorption transition around $500 \mathrm{~nm}$ (dashed line in Figure 1a), are converted into NCs that show efficient photoluminescence (PL) both in the visible (peak at $650 \mathrm{~nm}$ ) and in the NIR (peak at $900 \mathrm{~nm}$ ) (solid line in Figure 1a). The position of the first PL peak is in close agreement with that expected for directly synthesized $\mathrm{CuInS}_{2}$ (CIS) NCs of $2.5 \mathrm{~nm}$ (viz., $665 \mathrm{~nm}$ ). Further, PL lifetime measurements on the CIS NCs obtained by cation exchange (CE) yields lifetime values of $\tau_{1}=36 \mathrm{~ns}$ and $\tau_{2}=$ 206 ns (Figure 1b), which are comparable to those obtained on directly synthesized CIS NCs of comparable size and shape $\left(\tau_{1}=26 \mathrm{~ns}\right.$ and $\tau_{2}=205 \mathrm{~ns}$, Supporting Information Figure $\left.\mathrm{S}_{1}\right)$. Hence, the recombination pathways in the product CIS NCs obtained by $\mathrm{CE}$ in $\mathrm{Cu}_{2-\mathrm{x}} \mathrm{S}$ NCs are essentially the same as those in standard CIS NCs. Furthermore, the fact that the PL decay of directly synthesized CIS NCs and CIS NCs obtained by partial cation exchange show comparable values, indicates that there is no quenching of the PL of CIS NCs after partial CE. When the PL efficiencies of various CIS NCs were measured with an integrating sphere, a value of $5-7 \%$ was always obtained. We therefore state that the CIS NCs after CE also have a PL efficiency of that order of magnitude, which could be increased by shell overgrowth with widebandgap materials such as $\mathrm{CdS}$ and $\mathrm{ZnS}$ [ref Luca de Trizio and Klimov]. Usually, recombination in CIS NCs is ascribed to donor-acceptor pair (DAP) recombination, which explains the large global Stokes shift and relatively slow decay dynamics. ${ }^{23}$ It should be noted that the CIS NCs obtained by CE also show PL in the NIR (above 800 $\mathrm{nm}$ ). The PL lifetime measured for this band (at $796 \mathrm{~nm}$ ) is much longer $\left(\tau_{1}=42 \mathrm{~ns}\right.$ and $\tau_{2}=501 \mathrm{~ns}$, Supporting Information Fig $\mathrm{S}_{2}$ ), which is consistent with exciton recombination in trap states associated with surface and/or internal defects. We wish to note that the PL spectrum shown in Figure 1 is an ensemble measurements, which is averaged over a large number of single nanocrystals. We therefore expect that part of the nanocrystals have deeper trap states, giving rise to a second PL band in the NIR with characteristic longer lifetimes, typically associated with surface and/or internal defects. The limited resolution of the FEI Tecnai-12 TEM for particles smaller than $3 \mathrm{~nm}$ did not allow us to clearly visualize the $2.5 \mathrm{~nm}$ NCs. The formation of CIS NCs by partial cation exchange in $\mathrm{Cu}_{2-\mathrm{x}} \mathrm{S}$ NCs (2.5 $\mathrm{nm}$ diameter) is however confirmed by Energy Dispersive X-ray Spectroscopy (EDS, Supporting Information Fig $\mathrm{S}_{3}$ ) which reveals a $\mathrm{Cu}: \mathrm{In}: \mathrm{S}$ ratio of 1.0 $\pm 0.12: 1.4 \pm 0.16: 2$.
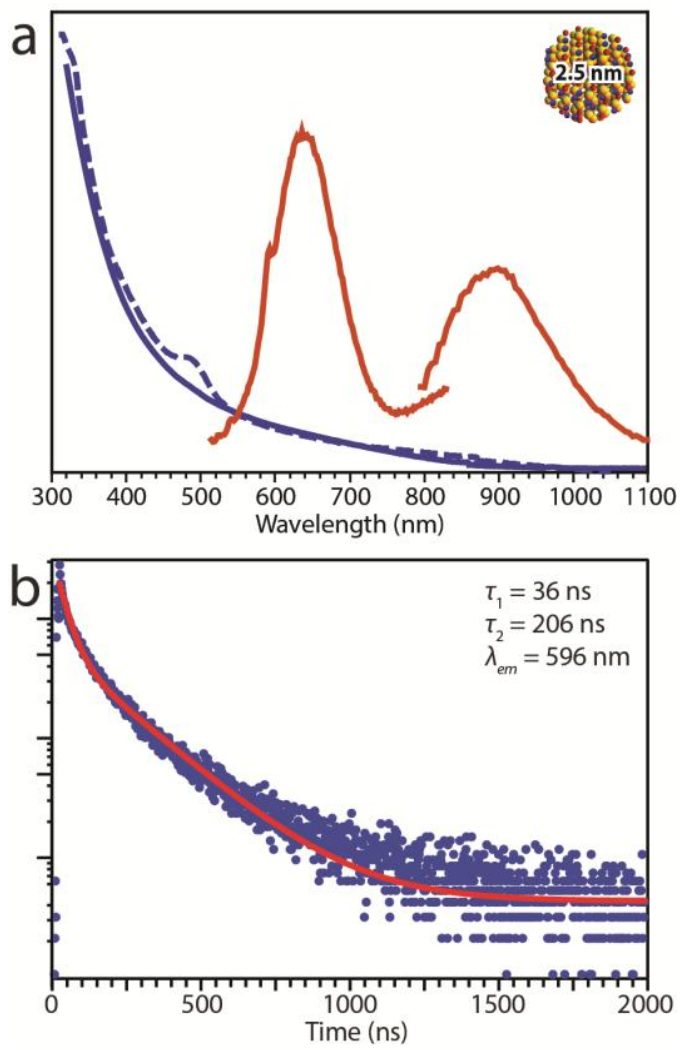

Figure 1. (a) Absorption and photoluminescence (PL) spectra of $2.5 \mathrm{~nm}$ CIS NCs obtained by partial cation exchange in $\mathrm{Cu}_{2-\mathrm{x}} \mathrm{S} \mathrm{NCs}$ (blue and red full lines). Two PL spectra are plotted due to the change of detector necessary to obtain a good signal in the NIR region. The absorption spectrum of the parent $2.5 \mathrm{~nm} \mathrm{Cu}_{2-\mathrm{x}} \mathrm{S} \mathrm{NCs}$ is also shown (blue dashed line). (b) PL decay of CIS NCs (2.5 nm) obtained by partial CE reactions. Fitting a bi-exponential to the data (red curve) yields a fast component with $\tau_{1}=36 \mathrm{~ns}$ and a slow component with $\tau_{2}=206 \mathrm{~ns}$.

$4 \mathrm{~nm}$ CIS NCs by partial cation exchange in $\mathrm{Cu}_{2-\mathrm{x}} \mathrm{S}$ NCs. The partial CE reaction was also exploited to convert larger $\mathrm{Cu}_{2-\mathrm{x}} \mathrm{S}$ parent NCs $(4 \mathrm{~nm})$ into CIS NCs. In this case, the product NCs show a PL peak in at $870 \mathrm{~nm}$ (Figure 2a). This clearly demonstrates that the NC size is 
inherited from the parent $\mathrm{Cu}_{2-\mathrm{X}} \mathrm{S} \mathrm{NCs}$, since this emission wavelength is consistent with CIS NCs with $4 \mathrm{~nm}$ in diameter. Considering that the optical properties are determined by the size of the CIS NCs, we can conclude that the method presented here provides a pathway to synthesize CIS NCs with efficient PL in the NIR, which have not yet been synthesized by direct synthesis protocols. Compared to the smaller NCs $(2.5 \mathrm{~nm})$, quantum confinement is relaxed leading to PL at lower energies. The PL decay of these larger (viz., $4 \mathrm{~nm}$ ) CIS NCs can be well described by a bi-exponential fit, with a fast component $\tau_{1}=68 \mathrm{~ns}$ and slow component $\tau_{2}=408$ ns (Figure 2b). These decay constants are slower than usually observed in small CIS NCs. This difference is qualitatively explained by Fermi's golden rule, ${ }^{34}$ according to which the spontaneous emission rate scales with the transition energy. More precisely, for excitonic transitions in NCs of varying sizes the radiative lifetime should scale linearly with the emission wavelength. ${ }^{35}$ The difference between the PL lifetimes of the two sizes of CIS NCs investigated here is however larger than predicted by Fermi's golden rule (emission wavelength ratio is 1.3, while the lifetime ratio is 1.9). This indicates that the emission transitions in CIS NCs are not excitonic in nature, but involve DAP recombination. ${ }^{23}$
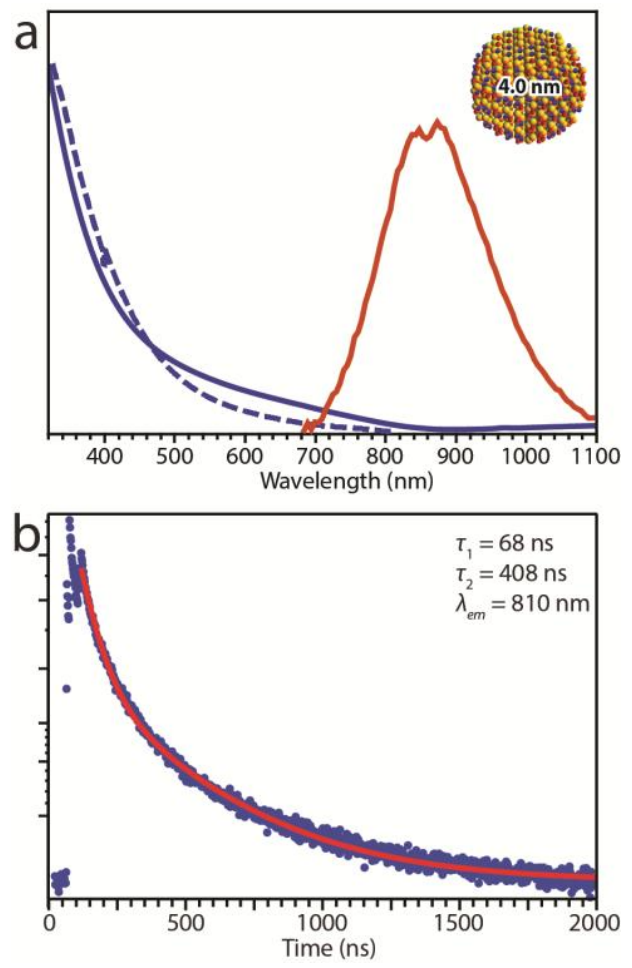

Figure 2. (a) Absorption and photoluminescence (PL) spectra of CIS NCs obtained by partial cation exchange in 4 nm diameter $\mathrm{Cu}_{2-\mathrm{x}} \mathrm{S} \mathrm{NCs}$ (blue and red full lines). The absorption spectrum of the parent $\mathrm{Cu}_{2-\mathrm{x}} \mathrm{S} \mathrm{NCs}$ is also shown (blue dotted line). (b) PL decay of $4 \mathrm{~nm}$ diameter CIS NCs obtained from $\mathrm{Cu}_{2-\mathrm{x}} \mathrm{S}$ NCs by $\mathrm{CE}$ reactions.. Fitting a biexponential to the data (red curve) yields a fast component with $\tau_{1}=68 \mathrm{~ns}$ and a slow component with $\tau_{2}=408 \mathrm{~ns}$.

TEM measurements revealed that the size of the parent $\mathrm{Cu}_{2-\mathrm{X}} \mathrm{S}$ NCs is preserved in the product CIS NCs (Figure 3).
The product NCs no longer form self-assembled superstructures on the TEM grid, suggesting that the size dispersion has slightly increased. It is also possible that the NC self-assembly is prevented by the presence of reaction by-products that were not completely removed by the washing procedure. The successful transformation of the parent $\mathrm{Cu}_{2-\mathrm{x}} \mathrm{S}$ NCs into product CIS NCs is clearly reflected in EDS measurements, where In peaks around $3.2 \mathrm{keV}$ are observed in the product NCs (Figure $3 \mathrm{~b}$ ). Quantification of the EDS measurements gives a $\mathrm{Cu}: \mathrm{S}$ ratio of $2 \pm 0.16$ $: 1$ for the parent $\mathrm{Cu}_{2-\mathrm{X}} \mathrm{S}$ NCs (Figure 3a) and a Cu:In:S ratio of 1.1 $\pm 0.14: 1.6 \pm 0.21: 2$ for the product CIS NCs (Figure $3 b$ ).

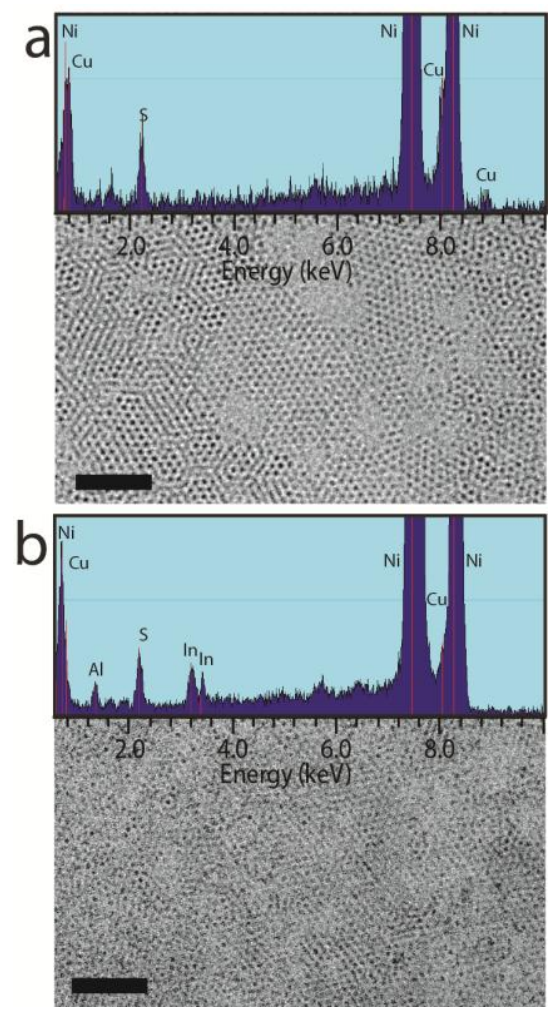

Figure 3. (a) Transmission Electron Microscopy (TEM) image of $4 \mathrm{~nm} \mathrm{Cu}_{2-\mathrm{x}} \mathrm{S}$ parent NCs. Inset displays the EDS spectrum of the $\mathrm{Cu}_{2-\mathrm{x}} \mathrm{S}$ parent NCs (b) TEM image of $4 \mathrm{~nm}$ CIS NCs, obtained from $\mathrm{Cu}_{2-\mathrm{S}} \mathrm{S}$ NCs by partial CE. Inset displays the EDS spectrum of the CIS NCs. Scale bars correspond to $50 \mathrm{~nm}$.

X-Ray Diffraction (XRD) measurements (Supporting Information, Fig $\mathrm{S}_{4}$ ) suggest that the $\mathrm{In}^{3+}$ for $\mathrm{Cu}^{+}$cation exchange in $\mathrm{Cu}_{2-\mathrm{x}} \mathrm{S} \mathrm{NCs}$ is accompanied by a crystal structure transformation from low-chalcocite $\mathrm{Cu}_{2-\mathrm{x}} \mathrm{S}$ to wurtzite CIS. The peaks are however severely broadened due to finite size effects, precluding a definite assignment of the observed reflections. Nevertheless, the formation of pure phase wurtzite CIS is unambiguously confirmed by HighResolution Scanning Transmission Electron Microscopy (HRSTEM) measurements (Figure 4). The $4 \mathrm{~nm}$ CIS product NCs were imaged along two crystallographic directions, viz.[10o] and [101].The images reveal the expected atomic arrangement for wurtzite CIS NCs. In Figure 4a, the $\mathrm{NC}$ viewed along the [100] direction is indicated by 
the red circle, whereas the $\mathrm{NC}$ viewed along the [101] direction is indicated by the blue circle. In the other panels, the same colors are used for the two directions, red for [10o] (Figure 4b,d,e) and blue for [101] (Figure 4c,f,g). When Fast Fourier Transformation (FFT) is calculated from the circled areas, the characteristic lattice of wurtzite CIS is directly evident in both cases (Figure 4b and c). When the images of the NCs from panel a are lattice averaged clear atomic positions are obtained (Figure $4 \mathrm{~d}$ and f). The observed atomic arrangement fits well with the wurtzite CIS crystal structure in both directions, as can be seen in the models depicted in Figure 4e and g, confirming the wurtzite crystal structure of the product $4 \mathrm{~nm}$ CIS NCs. Note that the contrast of the HAADF-STEM images is related to the atomic number so the contribution of In and $\mathrm{Cu}$ will dominate over $\mathrm{S}$. The resolution of the HRSTEM images is less than $3 \AA$ which further prevents resolving the $\mathrm{S}$ atoms from the $\mathrm{Cu} / \mathrm{In}$ atoms. The low resolution is due to poor beam stability of the material and severe contamination

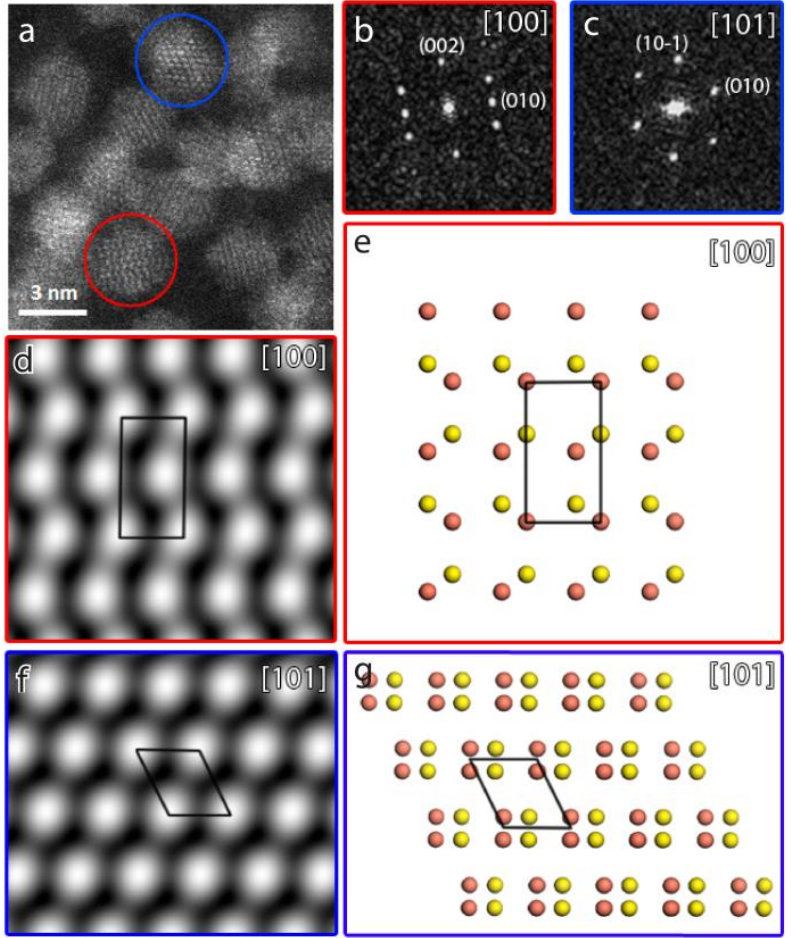

Figure 4.(a) High-Resolution Scanning Transmission Electron Microscopy (HRSTEM) image of the $4 \mathrm{~nm}$ product CIS NCs viewed along the [100] direction with respect to the electron beam (red circle) and along the [101] direction (blue circle) (b,c) Calculated FFTs from the areas indicated by the red circle (b)and by the blue circle (c). (d) Lattice averaged image from the red area in (a) reveal the atomic arrangement along the [100] direction. (e) The atomic arrangement fits well with the wurtzite CIS crystal structure. (f) Lattice averaged image of the blue area in (a) shows the atomic arrangement along the [101] direction. (g) The atomic arrangement fits well with the wurtzite CIS crystal structure. The yellow spheres denote the sulfur atoms and the orange spheres the $\mathrm{Cu} / \mathrm{In}$ atoms in $(\mathbf{e})$ and $(\mathbf{g})$.
$11 \mathrm{~nm}$ CIS NCs by partial cation exchange in $\mathrm{Cu}_{2-\mathrm{x}} \mathrm{S}$ NCs. To demonstrate that the method developed in this work can also yield CIS NCs of unprecedented sizes, we performed $\mathrm{CE}$ in $\mathrm{Cu}_{2-\mathrm{x}} \mathrm{S}$ NCs of $11 \mathrm{~nm}$. Although the product CIS NCs are non-luminescent due to their large size, the outcome of the CE reaction is more easily analysed with TEM and XRD. The UV-VIS absorption spectrum of the product NCs shows an absorption onset that is close to the bulk bandgap of CIS (1.4 eV, Figure 5a). It is also interesting to note that the NIR plasmon band associated with $\mathrm{Cu}$ vacancies in $\mathrm{Cu}_{2-\mathrm{x}} \mathrm{S}$ NCs disappeared after the $\mathrm{CE}$. Moreover, XRD measurements reveal a clear transition from the hexagonal low-chalcocite $\mathrm{Cu}_{2-\mathrm{x}} \mathrm{S}$ crystal structure to the hexagonal wurtzite CIS crystal structure (Figure 5 b), consistent with the observations discussed above for the $4 \mathrm{~nm}$ CIS NCs. The structural change is also clear in the electron diffraction patterns (Supporting Information, Figure $\mathrm{S}_{5}$ ). However, the size dispersion of the product CIS NCs is much larger than that of the parent $\mathrm{Cu}_{2-\mathrm{x}} \mathrm{S} \mathrm{NCs}$ (Supporting Information, Figure $\mathrm{S}_{5}$ ), suggesting that in this case CE was accompanied by partial dissolution and ripening. As will be discussed below, this indicates that there was a slight imbalance between the $\mathrm{Cu}^{+}$outgoing and the $\mathrm{In}^{3+}$ incoming rates.
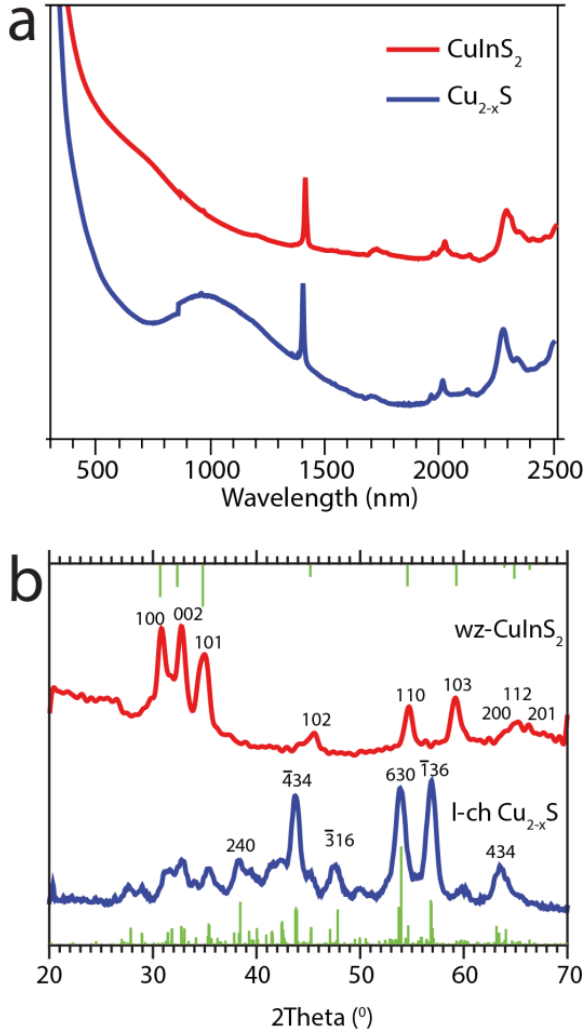

Figure 5. (a) Absorption spectrum of $11 \mathrm{~nm}$ CIS NCs obtained by cation exchange from $\mathrm{Cu}_{2-\mathrm{x}} \mathrm{S}$ NCs (red line). The absorption spectrum of the parent $11 \mathrm{~nm} \mathrm{Cu}_{2-\mathrm{x}} \mathrm{S} \mathrm{NCs}$ is also shown (blue line). (b) XRD patterns (Co K $\alpha$ source) of $11 \mathrm{~nm}$ CIS NCs obtained by cation exchange from $\mathrm{Cu}_{2-\mathrm{x}} \mathrm{S}$ NCs (wurtzite, wz, red line) and of the parent $\mathrm{Cu}_{2-\mathrm{x}} \mathrm{S}$ NCs (lowchalcocite, l-ch, blue line). Reference bars (green lines) are 
from JCPDS PDF-card o1-077-9459 for wurtzite CIS and R120113-9 for low-chalcocite. ${ }^{36}$

Mechanism. Cation exchange reactions consist of a chain of inherently linked elementary kinetic steps, that must proceed in a concerted manner. ${ }^{25,37}$ The driving force for the reaction is determined by the energy balance of the overall reaction, and therefore depends on the relative stabilities of the incoming and outgoing cations in solution and in the NC. It should also be noted that the cation exchange would not proceed beyond the surface in the absence of solid state diffusion fluxes in the $\mathrm{NC},,^{38}$ allowing the native cations to diffuse outwards and the new cations to diffuse inwards. The overall energy balance is thus also strongly dependent on the activation energies for diffusion of both the incoming and outgoing cations in the NC.

Figure 6 schematically depicts the elementary steps that can be identified in the $\mathrm{Cu}^{+}$for $\mathrm{In}^{3+}$ exchange in $\mathrm{Cu}_{2-}$ ${ }_{x} \mathrm{~S}$ NCs. It is interesting to note that the $\mathrm{Cu}^{+}$extraction and the $\mathrm{In}^{3^{+}}$incorporation proceed by separate chemical pathways, in contrast to other well-known nanoscale cation exchange reactions (e.g., $\mathrm{Cd}^{2+}$ for $\mathrm{Zn}^{2+}$ exchange in $\mathrm{ZnSe} \mathrm{NCs}$ using $\mathrm{Cd}(\text { oleate })_{2}$ ), in which the place exchange is mediated by a single ligand..$^{38}$ As a result, the extraction rate of the $\mathrm{Cu}^{+}$ions $\left(\mathrm{Cu}_{\text {out }}\right)$ and the incorporation rate of the $\mathrm{In}^{3+}$ ions $\left(\mathrm{In}_{\text {in }}\right)$ must be precisely balanced, otherwise the $\mathrm{NCs}$ will either dissolve $\left(\mathrm{Cu}_{\text {out }}\right.$ faster than $\left.\operatorname{In}_{\text {in }}\right)$ or the $\mathrm{CE}$ reaction will simply not proceed $\left(\mathrm{Cu}_{\text {out }}\right.$ too slow). Several $\mathrm{CE}$ experiments were carried out with small variations in the reaction conditions (i.e. higher temperatures of $50-100{ }^{\circ} \mathrm{C}$, higher concentration, different $\mathrm{CE}$ precursors and $\mathrm{Cu}$-extracting ligands), but these conditions failed to effectively convert $\mathrm{Cu}_{2-\mathrm{x}} \mathrm{S}$ NCs into CIS NCs, because the $\mathrm{Cu}^{+}$extraction rate was too fast compared to the $\mathrm{In}^{3+}$ incorporation rate, resulting in dissolution of the NCs. This highlights the sensitivity of the cation exchange process towards external synthetic conditions. Typically, phosphine ligands are used to extract $\mathrm{Cu}^{+}$ions from copper chalcogenides, due to the large binding energy of the soft Lewis base (trioctyl phosphine) to the soft Lewis acid $\mathrm{Cu}^{+}$. Extraction of $\mathrm{Cu}^{+}$results in a plasmon band in the $\mathrm{NIR}$, associated with free holes due to $\mathrm{Cu}$-vacancies. Other reports claim the combination of $\mathrm{Cu}^{+}$and free holes to effectively be $\mathrm{Cu}^{2+}$ ions, quenching the PL of CIS NCs. ${ }^{39}$ However, recent work by Manna and co-workers ${ }^{40}$ has unambiguously demonstrated that even in the most $\mathrm{Cu}$ deficient copper chalcogenide structure (covellite, $\mathrm{CuS}$ ), the oxidation state of the $\mathrm{Cu}$-ions is $\mathrm{1}+$ and that the nanocrystals are devoid of $\mathrm{Cu}^{2+}$. We note that in our work, the plasmon resonance present in larger nanocrystals disappears after cation exchange. This indicates that the $\mathrm{Cu}$ vacancies are filled with $\mathrm{In}^{3+}$ ions, reducing the amount of free holes. For smaller nanocrystals, this results in a PL in the visible or NIR region. Therefore, we state that TOP extracts the $\mathrm{Cu}^{+}$ions and generates vacancies which can be occupied by the $\mathrm{In}^{3+}$ ions, resulting in a solid state transformation of $\mathrm{Cu}_{2-\mathrm{x}} \mathrm{S}$ into $\mathrm{CuInS}_{2}$ nanocrystals.

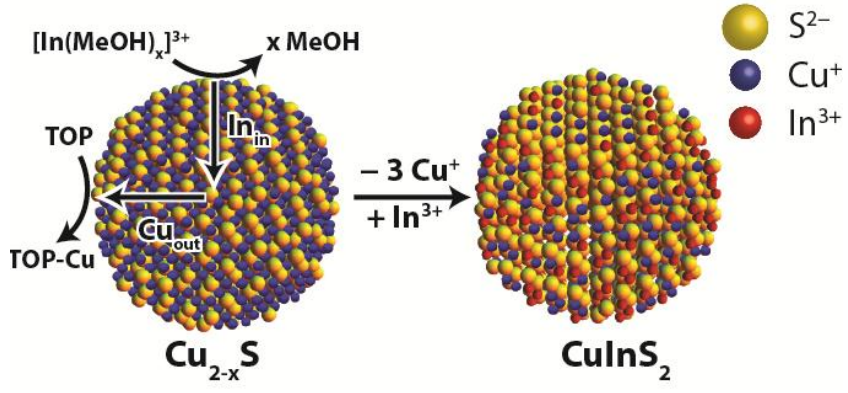

Figure 6. Schematic illustration of the elementary kinetic steps involved in conversion of $\mathrm{Cu}_{2-\mathrm{x}} \mathrm{S}$ nanocrystals into $\mathrm{CuInS}_{2}$ nanocrystals by $\mathrm{Cu}^{+}$for $\mathrm{In}^{3+}$ cation exchange. $\mathrm{Cu}^{+}$ extraction (mediated by trioctylphosphine, TOP) and $\mathrm{In}^{3+}$ incorporation into $\mathrm{Cu}^{+}$vacancies take place at the NC surface and set in motion two solid state cation diffusion fluxes (inwards diffusion of $\mathrm{In}^{3+}, \mathrm{In}_{\mathrm{in}}$, and outwards diffusion of $\mathrm{Cu}^{+}$, $\left.\mathrm{Cu}_{\text {out }}\right)$.

CE reactions are very often topotactic, preserving the crystal structure of the parent NCs into the product $\mathrm{NCs}^{23-27}$ More precisely, the anionic sublattice is conserved while the cations are exchanged. In this way, metastable crystal structures can be obtained, e.g. wurtzite $\mathrm{ZnS}$ starting from $\mathrm{Cu}_{2-\mathrm{x}} \mathrm{S}^{27}$ The present case is special, since partial $\mathrm{CE}$ is required in order to form the ternary CIS crystal structure rather than fully exchanged $\operatorname{In}_{2} \mathrm{~S}_{3}$ (in principle, the $\mathrm{In}: \mathrm{Cu}$ molar ratio of the $\mathrm{CE}$ reaction does allow full exchange to occur). This requires strict control over the incorporation and extraction rates of the cations. $\mathrm{Cu}_{2-\mathrm{x}} \mathrm{S}$ exists in multiple crystal structures, determined by the anionic arrangement and the concentration of $\mathrm{Cu}$ vacancies indicated by $\mathrm{x}$ (i. e. monoclinic low-chalcocite $\mathrm{Cu}_{2} \mathrm{~S}$, djurleite $\mathrm{Cu}_{1.96} \mathrm{~S}$ and roxbyite $\mathrm{Cu}_{1.78} \mathrm{~S}$, as well as hexagonal low- and high-chalcocite $\mathrm{Cu}_{2} \mathrm{~S}$, digenite $\mathrm{Cu}_{1.8} \mathrm{~S}$ and covellite $\left.\mathrm{CuS}\right) .^{39} \mathrm{~A}$ recent in situ X-ray study showed that small $\mathrm{Cu}_{2-\mathrm{x}} \mathrm{S} \mathrm{NCs}$ (diameter $<7 \mathrm{~nm}$ ) typically have the near-stoichiometric hexagonal high-chalcocite structure. $^{40}$ Our XRD measurements reveal a lowchalcocite crystal structure for $\mathrm{Cu}_{2-\mathrm{x}} \mathrm{S}$ particles of $11 \mathrm{~nm}$ in diameter (Fig 5b) and indicate a low-chalcocite crystal structure for $4 \mathrm{~nm} \mathrm{NCs}$ (Fig $\mathrm{S}_{4}$ ). The main difference between hexagonal low- and high-chalcocite is in the atomic positions of the $\mathrm{Cu}$-atoms, whereas the anions lie in a hexagonally close packed (hcp) arrangement in both cases. $^{36,41,42}$ Nanocrystalline CIS can attain two crystal structures, viz. roquesite and wurtzite. Roquesite is a zinc blende derivative where the sulfide anions are on a face centered cubic (fcc) sublattice, while wurtzite CIS is a hexagonal structure with a hcp anionic sublattice. CE reactions with djurleite and low- and high-chalcocite $\mathrm{Cu}_{2}$ ${ }_{x} \mathrm{~S} N C s$ as parent $\mathrm{NCs}$ are expected to result in wurtzite products, due to the hexagonal symmetry of the starting crystal structure. Hence, in our CE reaction wurtzite CIS $\mathrm{NCs}$ are favored over roquesite CIS, since the transformation of $\mathrm{Cu}_{2-\mathrm{x}} \mathrm{S}$ into the latter would require a substan- 
tial restructuring of the anionic sublattice. ${ }^{36,43}$ This is also confirmed by XRD and HRSTEM measurements discussed above.

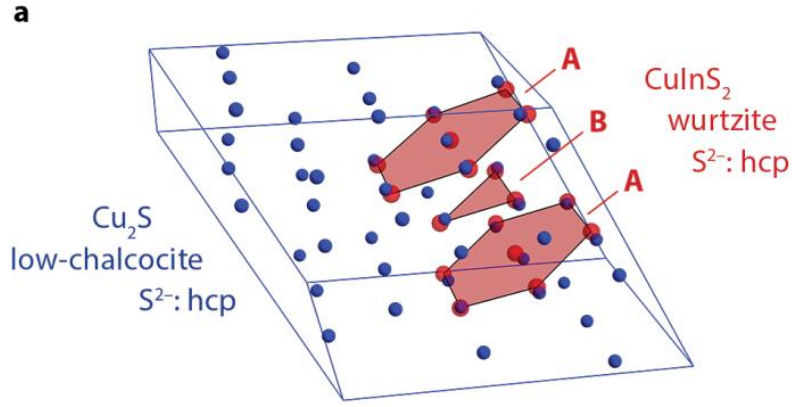

b

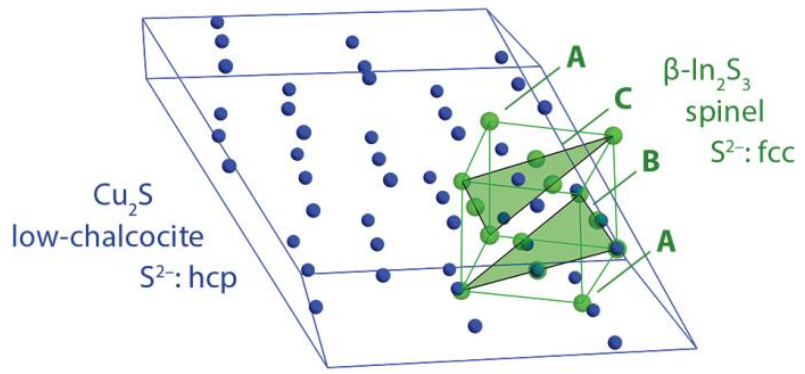

Figure 7. Comparison of the anionic sublattice of lowchalcocite $\mathrm{Cu}_{2-\mathrm{x}} \mathrm{S}$ with wurtzite CIS, showing that the anionic sublattice of low-chalcocite $\mathrm{Cu}_{2-\mathrm{x}} \mathrm{S}$ (blue spheres) is compatible with wurtzite CIS (red spheres), since both anionic sublattices have an hcp arrangement (a). Comparison of lowchalcocite unit cell (blue spheres) with $\operatorname{In}_{2} \mathrm{~S}_{3}$ (green spheres). The spinel $\mathrm{In}_{2} \mathrm{~S}_{3}$ structure has an fcc anionic sublattice, where layer $\mathrm{C}$ has to dislocate by $58 \%$ of a S-S distance in order to fit in the low-chalcocite lattice (b).

$\mathrm{In}_{2} \mathrm{~S}_{3}$ exists in three crystal structures, denoted as $\alpha, \beta$ and $\gamma$, where $\beta$ - $\operatorname{In}_{2} S_{3}$ is the stable structure up to $693 \mathrm{~K}^{44}$ All $\mathrm{In}_{2} \mathrm{~S}_{3}$ crystal structures have an fcc stacking of $\mathrm{S}^{2-}$ anions, but differ in the ordering of the ${\operatorname{~}{ }^{3+}}^{3+}$ cations. Hence, the anion sublattice is intrinsically different from hexagonal $\mathrm{Cu}_{2-\mathrm{x}} \mathrm{S}$ and wurtzite CIS, which is an important feature in avoiding full exchange from $\mathrm{Cu}_{2-\mathrm{x}} \mathrm{S}$ into $\mathrm{In}_{2} \mathrm{~S}_{3}$. Figure 7 compares the rearrangement of the anion sublattice required for the partial conversion of hexagonal lowchalcocite $\mathrm{Cu}_{2-\mathrm{x}} \mathrm{S}$ into wurtzite CIS (Fig 7a) to the full conversion of hexagonal low-chalcocite $\mathrm{Cu}_{2-\mathrm{x}} \mathrm{S}$ into $\beta-\mathrm{In}_{2} \mathrm{~S}_{3}$ (Fig $7 \mathrm{~b}$ ). Low-chalcocite $\mathrm{Cu}_{2-\mathrm{x}} \mathrm{S}$ and wurtzite CIS both have an hcp anion sublattice, with the hexagonal layers of $\mathrm{S}^{2-}$ anions $\mathrm{ABAB}$ stacked. This conversion requires a mere $1.4 \%$ contraction within the layers and $6.4 \%$ between the layers. The anions in $\beta$ - $\operatorname{In}_{2} S_{3}$ on the other hand, are $A B C$ stacked. Hence, the conversion from low-chalcocite to $\beta$ $\mathrm{In}_{2} \mathrm{~S}_{3}$ would require that four of every six anion layers shift over $58 \%$ of a S-S distance. Although such rearrangements from an hcp to an fcc anion sublattice have been demonstrated before ${ }^{45}$ they have high activation barriers and require high reaction temperatures. Consequently, the low reaction temperatures employed in this work limit the $C E$ to the extent that only partial exchange occurs, with luminescent ternary CIS as final product.

\section{Conclusions}

We show successful partial, self-limited cation exchange (CE) reactions from binary low-chalcocite $\mathrm{Cu}_{2-\mathrm{x}} \mathrm{S}$ $\mathrm{NCs}$ to luminescent ternary wurtzite $\mathrm{CuInS}_{2}$ (CIS) NCs. With this method, large CIS NCs of $4 \mathrm{~nm}$ can be obtained with photoluminescence (PL) in the near-infrared (NIR), which is not possible by direct synthesis protocols. Slow extraction of $\mathrm{Cu}^{+}$is essential, due to the balance between the $\mathrm{Cu}$-extraction rate and the slow incorporation rate of $\mathrm{In}^{3+}$. This slow $\mathrm{Cu}_{\text {out }}$ rate is achieved by choosing mild reaction temperatures. Furthermore, low reaction temperatures ensure that the $\mathrm{CE}$ is partial and prevent the formation of fully exchanged $\operatorname{In}_{2} S_{3}$. The method presented here may prove beneficial for several applications where shape selective deposition techniques are used to fabricate assembled $2 \mathrm{D}$ layers, for example in the field of photovoltaics or nanophotonics. The combination of multiple morphologies attainable for $\mathrm{Cu}_{2-\mathrm{x}} \mathrm{S} \mathrm{NCs}$ and the postsynthetic control over the composition towards CIS can thus result in the successful implementation of luminescent CIS NCs in several devices and in further tunability of the optoelectronic properties of CIS NCs. The problems arising from $\mathrm{Cd}$-based luminescent $\mathrm{NCs}$, such as toxicity, can be circumvented with this approach, which will prove beneficial for several applications in the field of photovoltaics, bio-imaging and lighting.

\section{REFERENCES}

1. Rogach, A. L.; Talapin, D. V.; Shevchenko, E. V.; Kornowski, A.; Haase, M.; Weller, H. Adv. Funct. Mater., 2002, 12, 653-664.

2. Donega, C. D. M. Chem. Soc. Rev., 2011, 40, 1512-1546.

3. Skrabalak, S. E.; Xia, Y. ACS Nano, 2009, 3, 10-15.

4. Talapin, D. V.; Murray, C. B. Science, 2005, 310, 86-89.

5. Zhao, Y.; van Rooy, I.; Hak, S.; Fay, F.; Tang, J.; de Lange Davies, C.; Skobe, M.; Allen Fisher, E.; Radu, A.; Fayad, Z. A.; de Mello Donega, C.; Meijerink, A.; Mulder, W. J. M. ACS Nano, 2013, 7, 10362-10370

6. Li, L.; Daou, T.; Texier, I.; Chi, T. K. Chem. Mater., 2009, 21, 2422-2429.

7. Bourzac, K. Nature, 2013, 493, 283.

8. Shirasaki, Y.; Supran, G.; Bawendi, M.; Bulović, V. Nat. Photonics, 2012, 7, 13-23.

9. Zhang, Y.; Xie, C.; Su, H.; Liu, J.; Pickering, S.; Wang, Y.; Yu, W. W.; Wang, J.; Wang, Y.; Hahm, J.; Dellas, N.; Mohney, S. E.; Xu, J. Nano Lett., 2011, 11, 329-332.

10. Kruszynska, M.; Borchert, H.; Parisi, J.; Kolny-Olesiak, J. J. Am. Chem. Soc., 2010, 132, 15976-15986.

11. Kolny-Olesiak, J.; Weller, H. ACS Appl. Mater. Interfaces, 2013, 5, 12221-12237.

12. Yarema, O.; Bozyigit, D.; Rousseau, I.; Nowack, L.; Yarema, M.; Heiss, W.; Wood, V. Chem. Mater., 2013, 25, 37533757 .

13. Reifsnyder, D. C.; Ye, X.; Gordon, T. R.; Song, C.; Murray, C. B. ACS Nano, 2013, 7, 4307-4315. 
14. Kim, S.; Kang, M.; Kim, S.; Heo, J.-H.; Noh, J. H.; Im, S. H.; Seok, S. Il; Kim, S.-W. ACS Nano, 2013, 7, 4756-4763.

15. Meillaud, F.; Shah, A.; Droz, C.; Vallat-Sauvain, E.; Miazza, C. Sol. Energy Mater. Sol. Cells, 20o6, 9o, 2952-2959.

16. Shockley, W.; Queisser, H. J. J. Appl. Phys., 1961, 32, 510.

17. Panthani, M. G.; Stolle, C. J.; Reid, D. K.; Rhee, D. J.; Harvey, T. B.; Akhavan, V. A.; Yu, Y.; Korgel, B. A. J. Phys. Chem. Lett., 2013, 4, 2030-2034.

18. Krumer, Z.; Pera, S. J.; van Dijk-Moes, R. J. A. ; Zhao, Y.; de Brouwer, A. F. P.; Groeneveld, E.; van Sark, W. G. J. H. M.; Schropp, R. E. I.; de Mello Donega, C. Sol. Energy Mater. Sol. Cells, 2013, 111, 57-65.

19. Erickson, C. S.; Bradshaw, L. R.; McDowall, S.; Gilbertson, J. D.; Gamelin, D. R.; Patrick, D. L. ACS Nano, 2014, 8, 34613467 .

20. Tan, J. M. R.; Lee, Y. H.; Pedireddy, S.; Baikie, T.; Ling, X. Y.; Wong, L. H. J. Am. Chem. Soc., 2014, 136, 6684-6692.

21. Kruszynska, M.; Borchert, H.; Parisi, J.; Kolny-Olesiak, J. J. Nanoparticle Res., 2011, 13, 5815-5824.

22. Panthani, M. G.; Akhavan, V.; Goodfellow, B.; Schmidtke, J. P.; Dunn, L.; Dodabalapur, A.; Barbara, P. F.; Korgel, P. A. J. Am. Chem. Soc., 20o8, 130, 16770-16777.

23. Zhong, H.; Zhou, Y.; Ye, M.; He, Y.; Ye, J.; He, C.; Yang, C.; Li, Y. Chem. Mater. 20o8, 20, 6434-6443.

24. Lu, X.; Zhuang, Z.; Peng, Q.; Li, Y. CrystEngComm., 2011, 13, 4040-4045.

25. Beberwyck, B. J.; Surendranath, Y.; Alivisatos, A. P. J. Phys. Chem. C, 2013, 117, 19759-19770.

26. Son, D. H.; Hughes, S. M.; Yin, Y.; Alivisatos, A. P. Science, 2004, 306, 1009-1012.

27. van der Stam, W.; Gantapara, A. P.; Akkerman, Q. A.; Soligno, G.; Meeldijk, J. D.; van Roij, R.; Dijkstra, M.; de Mello Donega, C. Nano Lett., 2014, 14, 1032-1037.

28. Li, H.; Zanella, M.; Genovese, A.; Povia, M.; Falqui, A.; Giannini, C.; Manna, L. Nano Lett., 2011, 11, 4964-4970.

29. Luther, J. M.; Zheng, H.; Sadtler, B.; Alivisatos, A. P. J. Am. Chem. Soc., 2009, 131, 16851-16857.

30. van der Stam, W.; Akkerman, Q. A.; Ke, X.; van Huis, M. A.; Bals, S.; de Mello Donega, C. submitted

31. Li, W.; Shavel, A.; Guzman, R.; Rubio-Garcia, J.; Flox, C.; Fan, J.; Cadavid, D.; Ibáñez, M.; Arbiol, J.; Morante, J. R.; Cabot, A. Chem. Commun., 2011, 47, 10332-10334.

32. Wang, Y.; Hu, Y.; Zhang, Q.; Ge, J.; Lu, Z.; Hou, Y.; Yin, Y. Inorg. Chem., 2010, 49, 6601-66o8.

33. Hovmöller, S. Ultramicroscopy, 1992, 41, 121-135.

34. Delerue, C.; Lannoo, M. Nanostructures - Theory and Modeling, Springer, 2004, 1st ed.

35 Donega, C.d. M.; Koole, R.; J. Phys. Chem. C, 2009, 113, 6511-6520.

36. (a) JCPDS card R120113-9 low-chalcocite $\mathrm{Cu}_{2} \mathrm{~S}$ (b) JCPDS card o1-077-9459 wurtzite CuInS $_{2}$ (c) JCPDS card oo-032$0456 \beta-\operatorname{In}_{2} \mathrm{~S}_{3}$

37. Rivest, J. B.; Jain, P. K. Chem. Soc. Rev., 2013, 42, 89-96.
38. Groeneveld, E.; Witteman, L.; Lefferts, M.; Ke, X.; Bals, S.; van Tendeloo, G.; Donega, C. d. M. ACS Nano, 2013, 7, 79137930 .

39. Chakrabarti, D.J.; Laughlin, D.E. Bull. Alloy Phase Diagrams, 1983, 4, 254-270.

40. Noerby, P.; Johnsen, S.; Iversen, B. B. ACS Nano, 2014, $8,4295-4303$.

41. Buerger, M. J. , and Wuensch, B. J. Science, 1963, 141, 276-277.

42. Evans, H. T. Nature, 1971, 232, 69-70.

43. Wyckoff, R. W. G. Structure of Crystals, American Chemical Society Monograph Series, 1935

44. Diehl, R.; Nitsche, R. J. Cryst. Growth, 1975, 28, 306-310.

45. Huang, X.; Li, S.; Huang, Y.; Wu, S.; Zhou, X.; Li, S.; Gan, C. L.; Boey, F.; Mirkin, C. A.; Zhang, H. Nat. Commun., 2o11, $2,1-6$

\section{ASSOCIATED CONTENT}

Supporting Information. Photoluminescence (PL) decay of directly synthesized $2.5 \mathrm{~nm}$ CIS NCs, near-infrared PL decay of $2.5 \mathrm{~nm}$ CIS NCs, Energy Dispersive X-ray Spectroscopy (EDS) spectrum of $\mathbf{2 . 5} \mathrm{nm}$ CIS NCs, X-ray Diffraction measurements of $4 \mathrm{~nm} \mathrm{Cu}_{2-\mathrm{x}} \mathrm{S}$ and CIS NCs and Transmission Electron Microscopy (TEM), Electron diffraction (ED) measurements and particle size histograms of large $11 \mathrm{~nm} \mathrm{Cu}_{2-\mathrm{x}} \mathrm{S}$ and CIS NCs. This material is available free of charge via the Internet at http://pubs.acs.org.

\section{AUTHOR INFORMATION}

\section{Corresponding Author}

*c.demello-donega@uu.nl

\section{Author Contributions}

The manuscript was written through contributions of all authors.

\section{ACKNOWLEDGMENT}

W.v.d.S. and C.d.M.D. acknowledge financial support from the division of Chemical Sciences (CW) of the Netherlands Organization for Scientific Research (NWO) under grant number ECHO.712.012.001. S.B. and T. W. acknowledge financial support from European Research Council (ERC Starting Grant \#335078COLOURATOMS).The authors also appreciate financial support from the European Union under the Seventh Framework Program (Integrated Infrastructure Initiative N. 262348 European Soft Matter Infrastructure, ESMI). The authors thank Josine Bulle for the synthesis of $4 \mathrm{~nm}$ $\mathrm{Cu}_{2-\mathrm{x}} \mathrm{S}$ NCs, Gang Wang, MSc, for XRD measurements and Joost van der Lit, MSc, for image processing assistance. 